\title{
A.JO'厂E
}

African Journal of Teacher Education

ISSN 1916-7822. A Journal of Spread Corporation

$\begin{array}{llll}\text { Vol. } 7 & \text { No. } 2018 & \text { pp. 53-66 }\end{array}$

\section{Family Socioeconomic Status, Religiosity and Alcohol Use among Secondary School Adolescents in Bushenyi Ishaka Municipality, Uganda}

\author{
Athanansio Bashaija \\ Ankole Western University, Uganda \\ sbashaija@awu.ac.ug \\ $\&$ \\ Aloysius Rukundo \\ Mbarara University of Science and Technology, Uganda
}

\begin{abstract}
This paper reports research on levels of family socioeconomic status, religiosity and alcohol use among secondary school adolescents in Bushenyi Ishaka Municipality, Uganda (BIM). The study employed a cross- sectional survey design with quantitative method of data collection and analysis. Proportionate stratified, and systematic simple random sampling techniques were used to arrive at the final sample of participants. Data was collected using a self-administered questionnaire with standardized scales. The instrument comprised Bio-data, SES scale, religiosity, spiritual scale for Youth, and AUDIT Test for Alcohol use. Responses were obtained from a total of 404 participants who included females as the majority $(54.7 \%)$. The mean age of the students was 15.91 . Results show that majority of the students came from families with moderate levels of socioeconomic status. It was further discovered that students had low levels of alcohol use and high levels of religiosity. Implications of the study findings are discussed.
\end{abstract}

\section{Keywords}

Family Socioeconomic Status (SES), Alcohol Use, Religiosity, Adolescents, Psychoactive Substance. 


\section{Background}

Adolescence is a critical stage in the life-course and can be considered the most transformative period in the individual's lifespan. At this critical period, students begin to experiment with experiences including alcohol use (Carter et al, 2007). Alcohol is the most commonly used psychoactive substance in secondary schools, compared to other drugs globally (Rehm et al., 2009). Many people initiate alcohol and drug use during their years as teenagers (Carter et al., 2007). The use of alcohol among adolescents from different socio-economic statuses is a public health concern. Collins et al. (2012) posit that socioeconomic status (SES) is one of the major factors influencing a person's alcohol use and related outcomes. Socioeconomic status (SES) is often measured as a combination of education, income and occupation. It is commonly conceptualized as the social standing or class of an individual or group. When viewed through a social class lens, privilege, power, and control are emphasized (Aggarwal, et al., 2005). It has been discovered that socio-economic status influences the frequency of alcohol use among adolescents (Collins et al, 2012). In societies with low socio-economic level, where immigration and unemployment is intensive, factors such as harsh living conditions, familial conflict due to financial strain, coping ability of individuals and depression direct adolescents towards alcohol use (Goodman \& Huang, 2002).

Although some researchers report that alcohol use is observed more frequently in societies with low socio-economic status, others report that it can be obtained more easily and consumed more commonly by those at high socioeconomic levels (Tot et al., 2004). Three cross-sectional studies done USA and Canada show that adolescents growing up in higher SES families were more likely to use alcohol than those born in lower SES families (Blum et al., 2000; Humensky, 2010; Hanson \& Chen, 2007). For high SES adolescents, family income is a stronger predictor of alcohol use than family status (Hanson \& Chen, 2007). Hanson \& Chen (2007) further posit that the availability of financial resources is more influential on teen alcohol use than the social status associated with having parents with high education and good jobs. It is indicated that people with higher SES may consume similar or greater amounts of alcohol compared to people with lower SES, although the latter group seems to bear a disproportionate burden of negative alcohol-related consequences (Collins et al, 2012). Wills et al. (2003) on the other hand assert that the education level of an individual's family has an effect on alcohol use in adolescence. It is found that high 
Family Socioeconomic Status, Religiosity and Alcohol Use among Secondary School Adolescents in Bushenyi Ishaka Municipality, Uganda

education level of parents is related to increased alcohol use and rate of getting drunk (O'Malley, Johnston, \& Bachman, 1998).

Considerable variation in the prevalence of alcohol use among adolescents exists between countries (Kokkevi, 2007). While alcohol use among adolescents tends to be higher among adolescents from the more developed countries (Benjet, 2007), lack of solid data from the less developed countries makes comparisons difficult. The data available from less developed countries suggest that the drug abuse problem among youth both in school and out of school is on the increase (Mndeme, 2003; Kaduri, 2008; Mbatia \& Kilonzo, 1996). Chikere and Mayowa (2011) found that in a number of school surveys in Nigeria, alcohol use is the most common among students, with many drinking students having had their first drink in familial settings. The 2003 Ugandan GSHS findings show that $14 \%$ and 12\% of boys and girls aged 13-15 years respectively reported having ever drunk so much alcohol that they were really drunk (Kabiru, 2010). On the other hand, the study conducted among school-going adolescents aged 11-17 years in Uganda, indicated that $18 \%$ of the adolescents reported having ever consumed alcohol (Rudatsikira, 2007).

In Africa, various populations and individuals are mostly adherents of Christianity, Islam, and to a lesser extent Traditional African religion. In Christian or Islamic communities, religious beliefs are also sometimes characterized with syncretism, beliefs and practices of traditional religions (Tewahedo \& Tijaniyyah, 2015). According to the Bureau of Democracy, Human Rights, and Labor (2009), an estimated $85 \%$ of the population in Uganda was Christian, $12 \%$ is Muslim, and the remaining 3\% follow indigenous and other beliefs (Hinduism, Baha'ism, and Judaism). Of the Christian population, the Roman Catholic Church had the largest number of followers (42\%) followed by Anglican (36\%). Empirical data on levels of family SES, alcohol use, and religiosity among secondary school adolescents in rural Uganda is lacking. This study was carried out to find out the levels of SES, alcohol use and religiosity among secondary school adolescents in Bushenyi Ishaka Municipality.

\section{Methodology}

The research for this paper adopted a cross-sectional survey design. It is quantitative in nature and meaningfully describes the distribution of variables using standard procedures of frequencies and percentage. Bushenyi- Ishaka Municipality in South Western Uganda has 13 schools; 4 government and 9 private. The schools for the study were selected through a proportionate 
stratified sampling technique. Uganda's post-primary education is structured into two levels; the first level lasting four years (Senior 1 -Senior 4) and the second senior level, two more years (Senior 5 and Senior 6) before admittance into the university or vocational institutions. The schools exist in the two categories of government/public and private. Proportionate Stratified sampling was used to select six secondary schools; three private and three public. The study sampled 404 students, 293 students from government schools and 111 students from private schools drawn from a population of 3012 ordinary level students in secondary schools, using systematic simple random sampling. The study population consisted of students of both private schools which are owned by individuals and public secondary schools owned by the government of Uganda aged from 11 to 20. The data collection instrument was a structured, self-administered questionnaire

The scale for measuring the Socioeconomic Status of Family (Aggarwal, Bhasin, Sharma, Chhabra, Aggarwal, \& Rajoura, 2005) was used to collect data on Family SES. The composite reliability coefficient of SES scale was $\alpha=$.78. It has 22 items scored from zero to maximum of 10 points regarding the possessions of a family. The 22 items are based on three variables of income, education, and occupation of the family head. Religiosity and spiritual scale for Youth (Brittany \& Hernandez, 2011) was used to collect data on religiosity. The composite reliability coeffic ie nt of religiosity scale is $\alpha=.95$. It has 37 items scored on a four point likert scale of $0=$ Never to 3=Always. AUDIT Test for Alcohol use (Saunders, Aasland, Babor, de la Fuente, \& Grant, 2001) was used to collect data on alcohol use among adolescents. The composite reliability coeffic ient of Alcohol use scale is $\alpha=.89$. The alcohol use scale by (Saunders et al, 2011) has 10 items scored on a five point likert scale from $0=$ Never to $4=$ Daily or Almost Daily. Data were analyzed using SPSS software, version 20.0. The results are presented using descriptive statistics in the form of percentages and frequencies. 
Family Socioeconomic Status, Religiosity and Alcohol Use among Secondary School Adolescents in Bushenyi Ishaka Municipality, Uganda

\section{Results}

Table 1: Respondents Demographics

\begin{tabular}{|c|c|c|c|c|c|}
\hline \multicolumn{2}{|c|}{ Class $(\mathrm{N}=404) \quad n(\%)$} & Gender $(\mathrm{N}=404)$ & $\mathrm{n}(\%)$ & $\begin{array}{l}\text { Religious } \\
\text { Affiliation( } N=404)\end{array}$ & $\mathrm{n}(\%)$ \\
\hline Senior one & $96(23.8)$ & & & Catholics & $117(29.0)$ \\
\hline Senior two & $119(29.5)$ & Male & $183(45.3)$ & Protestants & $175(43.3)$ \\
\hline Senor three & $64(15.8)$ & Female & $221(54.7)$ & Moslems & $34(8.4)$ \\
\hline Senior four & $125(30.9)$ & Total & $404(100.0)$ & SDA & $73(18.1)$ \\
\hline Total & $404(100.0)$ & & & Others & $5(1.2)$ \\
\hline $\operatorname{Age}(N=404)$ & n (\%) & $\begin{array}{l}\text { Type of } \\
\text { School }(N=404)\end{array}$ & $\mathrm{n}(\%)$ & & \\
\hline 11 & $4(1.0)$ & Government & $291(72.0)$ & & \\
\hline 12 & $7(1.7)$ & Private & $113(28.0)$ & & \\
\hline 13 & $25(6.2)$ & $\begin{array}{l}\text { Nature of } \\
\operatorname{school}(N=404)\end{array}$ & $\mathrm{n}(\%)$ & & \\
\hline 14 & $65(16.1)$ & $\begin{array}{ll}\text { Day } & \text { and } \\
\text { boarding }\end{array}$ & $124(30.7)$ & & \\
\hline 15 & $75(18.6)$ & Boarding only & $280(69.3)$ & & \\
\hline 16 & $79(19.6)$ & $\begin{array}{l}\text { School } \\
\text { section }(N=404)\end{array}$ & $\mathrm{n}(\%)$ & & \\
\hline 17 & $69(17.1)$ & Boarder & $350(86.6)$ & & \\
\hline 18 & $37(9.2)$ & Day scholar & $54(13.4)$ & & \\
\hline 19 & $23(5.7)$ & & & & \\
\hline 20 & $20(5.0)$ & & & & \\
\hline Mean age & 15.91 & & & & \\
\hline $\begin{array}{l}\text { Standard } \\
\text { deviation }\end{array}$ & 1.93 & & & & \\
\hline
\end{tabular}

Table 2: Levels of Family Socioeconomic Status

\begin{tabular}{lll}
\hline Levels of SES & Frequency & Percentage \\
\hline Poor & 3 & .7 \\
Lower middle & 67 & 16.6 \\
Upper middle & 178 & 44.1 \\
High & 126 & 31.2 \\
Upper high & 30 & 7.4 \\
Total & 404 & 100.0 \\
\hline
\end{tabular}


Table 3: Levels of Alcohol Use

\begin{tabular}{ccl}
\hline Levels of Alcohol Use & Frequency & Percent \\
\hline Low use & 353 & 87.4 \\
Moderate use & 47 & 11.6 \\
High use & 4 & 1.0 \\
Total & 404 & 100.0 \\
\hline
\end{tabular}

Table 4: Kruskal-Wallis Test $\mathrm{H}\left(\chi^{2}\right)$ and Mann-Whitney U Tests for students' demographics on the Levels of Alcohol Use

\begin{tabular}{|c|c|c|c|c|c|c|c|}
\hline Variable & Demographic & & $\begin{array}{l}N \\
(404)\end{array}$ & $\begin{array}{l}\text { Mean } \\
\text { Rank }\end{array}$ & $\mathbf{H}\left(\chi^{2}\right) / \mathbf{U}$ & $\overline{\mathbf{P}}$ & $\overline{\text { Decision }}$ \\
\hline \multirow{27}{*}{ 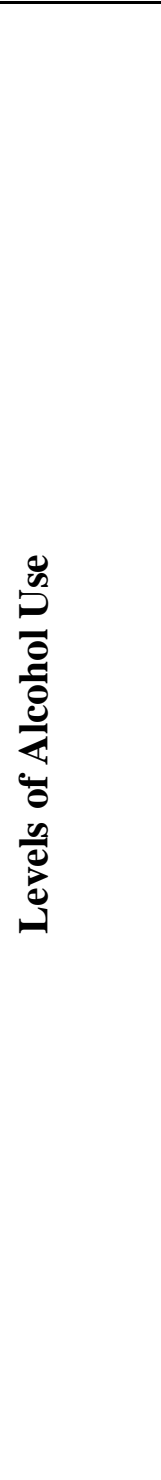 } & \multirow[t]{2}{*}{ Gender } & Male & 183 & 221.13 & \multirow[t]{2}{*}{$16811.500^{\mathrm{u}}$} & \multirow[t]{2}{*}{.000} & \multirow[t]{2}{*}{ *** } \\
\hline & & Female & 221 & 187.07 & & & \\
\hline & \multirow{4}{*}{$\begin{array}{l}\text { Class of } \\
\text { Respondents }\end{array}$} & Senior one & 96 & 185.33 & \multirow{4}{*}{9.403} & \multirow{4}{*}{.024} & \multirow{4}{*}{$* *$} \\
\hline & & Senior two & 119 & 212.29 & & & \\
\hline & & Senor three & 64 & 209.05 & & & \\
\hline & & Senior four & 125 & 203.01 & & & \\
\hline & \multirow[t]{10}{*}{ Age } & 11 & 4 & 177.00 & \multirow{10}{*}{16.920} & \multirow{10}{*}{.050} & \multirow{10}{*}{$* *$} \\
\hline & & 12 & 7 & 179.57 & & & \\
\hline & & 13 & 25 & 177.00 & & & \\
\hline & & 14 & 65 & 186.23 & & & \\
\hline & & 15 & 75 & 206.33 & & & \\
\hline & & 16 & 79 & 220.36 & & & \\
\hline & & 17 & 69 & 200.56 & & & \\
\hline & & 18 & 37 & 200.00 & & & \\
\hline & & 19 & 23 & 194.39 & & & \\
\hline & & 20 & 20 & 227.00 & & & \\
\hline & \multirow{2}{*}{$\begin{array}{l}\text { Type of a } \\
\text { School }\end{array}$} & Government & 291 & 206.90 & \multirow[t]{2}{*}{$15160.000^{\mathrm{u}}$} & \multirow[t]{2}{*}{.035} & \multirow[t]{2}{*}{$* *$} \\
\hline & & Private & 113 & 191.16 & & & \\
\hline & \multirow[t]{2}{*}{$\begin{array}{l}\text { Nature of } \\
\text { School }\end{array}$} & $\begin{array}{l}\text { Day and } \\
\text { boarding }\end{array}$ & 124 & 191.72 & \multirow[t]{2}{*}{4.601} & \multirow[t]{2}{*}{.032} & \multirow[t]{2}{*}{$* *$} \\
\hline & & $\begin{array}{l}\text { Boarding } \\
\text { only }\end{array}$ & 280 & 207.27 & & & \\
\hline & \multirow{2}{*}{$\begin{array}{l}\text { Boarder or } \\
\text { a Day } \\
\text { Scholar }\end{array}$} & Boarder & 350 & 200.65 & \multirow[t]{2}{*}{$8801.500^{\mathrm{u}}$} & \multirow[t]{2}{*}{.158} & \multirow[t]{2}{*}{$\mathrm{ns}$} \\
\hline & & Day scholar & 54 & 214.51 & & & \\
\hline & Religious & Catholic & 117 & 207.99 & \multirow{5}{*}{1.541} & \multirow{5}{*}{.819} & \multirow{5}{*}{ ns } \\
\hline & \multirow[t]{4}{*}{ Affiliation } & Protestants & 175 & 198.86 & & & \\
\hline & & Moslem & 34 & 201.28 & & & \\
\hline & & SDA & 73 & 202.01 & & & \\
\hline & & Others & 5 & 217.00 & & & \\
\hline
\end{tabular}


Family Socioeconomic Status, Religiosity and Alcohol Use among Secondary School Adolescents in Bushenyi Ishaka Municipality, Uganda

Table 5: Levels of Religiosity

\begin{tabular}{ccc}
\hline Levels of Religiosity & Frequency & Percent \\
\hline Low religiosity & 15 & 3.7 \\
High religiosity & 389 & 96.3 \\
Total & 404 & 100.0 \\
\hline
\end{tabular}

From findings in Table 1, majority of the study participants were females (54.7\%). Most of the respondents were boarders $(86.6 \%)$. In addition, most of the students $(69.3 \%)$ were attending Boarding schools while $30.7 \%$ were in Day and Boarding schools. $28.0 \%$ of the study participants were from private schools while $72.0 \%$ were from government schools. Majority of the study participants were from senior four, (30.9\%). Respondents' age shows (19.6\%) sixteen years old as the majority. With regard to religious inclination, a total of 175(43.3\%) were Protestants as the majority. In the table 2 , it was observed that few of the respondents $(0.7 \%)$ belonged to poor SES and most of the respondents belonged to upper middle (44.1\%), followed by (31.2\%) to high SES. From the findings in table 3 , most of the respondents $353(87.4 \%)$ reported low use and few respondents $(1.0 \%)$ reported high use.

Results showing demographic differences in the levels of alcohol use are presented in Tables 4. It is observable from Table 4, that all values of demographics of gender, class of respondents, age of respondents, type of a school, and nature of school, are significant whereas demographics of capturing whether respondents were boarders or day scholars and their religious affiliations show non-significant results. Findings on gender differences in the levels of alcohol use shows that male students show relatively higher mean rank values (221.13) than females (187.07) implying that more males than females use alcohol.

Regarding differences in students' classes, it is observed that Senior Two students and senior three students have relatively the highest mean rank values (212.29 and 209.05 respectively), compared to other classes. With respect to students' age differences, it is shown that there were significant age differences in alcohol use. The results depict students aged 20 have the highest mean rank, followed by those aged 16. The results in Table 4 also tend to suggest that students aged $14 \mathrm{~s}$ and above have higher chances of consuming alcohol than those below the age of 14. Regarding the nature of a school, students in only boarding schools have highest mean rank (207.27) compared to day and boarding schools with mean rank (191.72). As regards to whether one is a boarder or a day scholar, results shows that there is no significant difference $(\mathrm{p}=.158) \ldots$ It is seen from the findings that there is no significant religious difference in alcohol use.

From the findings in table 5, most of the respondents (96.3\%) reported high religiosity, and only $(3.7 \%)$ reported low religiosity using a sample of 404 aged 11 to 20 year 


\section{Discussion}

\section{Levels of Family Socioeconomic Status of BIM Students}

The results revealed that majority of the respondents had moderate levels of socioeconomic status, followed by high levels and just a few belong to poor SES. This is in line with Aggarwal, et al. (2005) who found that of all strata of the society in India, many families belonged to middle SES followed by high and a few to poor SES. However, these results contradict other findings from four sub-Saharan African countries by Jacob and Justice (2012) which found that many of the respondents had poor levels of SES compared to those in high SES. In fact, according to Jacob and Justice, $12 \%$ of the participants from Ghana were in the highest wealth index quintile while about $32 \%$ were in the lowest quintile. Similarly, $14 \%$ of respondents in Nigeria were in the highest quintile relative to about $26 \%$ in the lowest quintiles. In Kenya, about $21 \%$ and $29 \%$ of respondents were in the richest and poorest wealth index quintiles, respectively. Sierra Leone had approximately $18 \%$ of respondents in the richest wealth quintile and about $22 \%$ in the poorest quintile. A possible explanation for these surprising results could be that many of the respondents come from western Uganda where many guardians are neither poor nor very rich compared to other parts of the country. Research indicates that children from low-SES households and communities develop academic skills more slowly compared to children from higher SES groups (Morgan, Farkas, Hillemeier, \& Maczuga, 2009). Initial academic skills are correlated with the home environment, where low literacy environments and chronic stress negatively affect a child's pre-academic skills. The school systems in low-SES communities are often under resourced, negatively affecting students' academic progress (Aikens \& Barbarin, 2008). Inadequate education and increased dropout rates are correlated and do perpetuate the low-SES of the community.

\section{Levels of Alcohol Use among BIM Students}

The students had a generally low levels of alcohol use (see Table 3). This could be because of high levels of religiosity the students reported in Table 4 and moderate family SES. Therefore, student's religiosity may be protective of students from involving themselves in drinking alcohol. This concurs with Sanchez, Oliveira, and Nappo's (2008) findings that considered religiosity as a protective factor against alcohol use. Sanchez and others, found that high levels of religiosity prevent individuals from using drugs even if they live in perilous environments. Al-Kandari, Yacoub, and Omu's (2001) study also show that religiosity was identified as protective as almost all the participants in their study emphasized the role of religious beliefs and practices in protecting against risky behaviors, including alcohol abuse. This Ugandan findings on low alcohol use level however, diverges from a study by Cartelet al. (2007) that reported high levels of alcohol use in secondary schools [in Belgium]. 75.4\% of the Flemish scholars (12-18 years) had drunk alcohol at least once during their lifetime. A vast majority of the respondents (63.4\%) even used alcohol during the past 12 months, of which $22 \%$ drank alcohol on a regular basis, that is, more than once a week. 
Data from industrialized countries contradicts findings that excessive alcohol use often begins at young age (11-14). According to WHO (2012), 46\% of the world's adolescents aged 1519 years reported having ever used alcohol, and $34 \%$ had used it in the last year. In other subSaharan African countries like Kenya, ever drinking prevalence of up to $15 \%$ were found among secondary school students. A study from South Africa also reported an alcohol use prevalence of 39.1\% among high school adolescents (Madu \& Matla, 2003). A study by Simbee (2012) revealed that a significant number of youth in Dodoma Tanzania use alcohol frequently, as $59.0 \%$ of them used alcohol between one and five days a week while the remainder (31.0\%) used it more than 20 days a month. Another survey conducted by John and Guiella (2006) among 5,112 adolescents between the ages of 12-19 years in 2004 in Uganda revealed that 33\% of them have tried alcohol. That study indicates that about a third of those that drink alcohol reported being drunk in the past 12 months. This result diverges from the findings from our study in which many respondents reported low levels of alcohol use possibly influenced by the high levels of religiosity reported by students. It might also be because $86 \%$ of the sampled student population were in boarding schools and were thus less exposed to risky behaviors including alcohol consumption.

Further analysis was done to know whether differences exist in the students' demographics on the levels of alcohol use. The study results (Table 1) show that majority of the respondents were females compared to males. This agrees with the findings of Marklein (2005), Mather and Adams (2007), \& Holder (2009) that there are generally more female students than males in schools [where?]. However, the results in Table 4 show that significant gender differences exist in alcohol use as male students consume more alcohol than females. This observation however is illuminated by traditional gender roles in typical Uganda communities. These societies raise females to be submissive and to restrain from what they consider non-feminine behaviors, including alcohol use. Therefore, gender is an important factor affecting drinking behavior among adolescents, and that in almost every society, adolescent males drink more often than adolescent females (Ahlström \& Österberg, 2004).

The results also show significant class differences in alcohol use. Those who are in senior two have the highest mean ranges, compared to other classes implying that senior two students consume alcohol than other classes. Use of alcohol is typically a peer-influenced and experimental behavior, which could be at its peak during early adolescence-when students are in senior two. This finding could signify that students in senior four with relatively low level of alcohol use who are at the time of completing their UCE are overwhelmed by the academic pressure of the limited time left preparing to seat for their final year exam (Waeytens, Hulpiau, \& Jan, 2002). Results in Table 1 further revealed that majority of the students were (boarders), a situation probably minimized exposure of the adolescents to risky behaviors like alcohol drinking. Boarders experienced higher levels of discipline and supervision at school compared to day scholars whose daily commute to school is fraught with a lot of challenges. Thus, day scholars have the highest mean rank compared to boarders who have the least mean rank; day scholars being users of more 
alcohol than boarders. This thus explains why the majority of the interviewed students reported low levels of alcohol use. Most of the respondents were boarders.

\section{Levels of Religiosity among Secondary School Adolescents of BIM}

Most of the respondents had high religiosity, and only a few had low religiosity. This fits with the global trend, as high levels of religiosity are exhibited worldwide among adolescents (Sanchez, Oliveira \& Nappo, 2008). According to the Pew Research Center (2015), the majority of Americans (70.6\%) identify themselves as more religious. In addition, religion in the European Union is a serious matter with significant levels of belief in all EU member states (Special Eurobarometer, 2010). The largest religion in the EU is Christianity, which accounts for $72 \%$ of EU population, with its largest denominations being Roman Catholicism, Protestantism (especially in the north), and Eastern Orthodoxy

The majority of Africans are also adherents of Christianity or Islam; though many often combine the practice of their traditional belief with the practices of Christianity and Islam (Mbiti, 1992; Riggs, 2006). These Abrahamic religions are widespread throughout Africa. They have both spread and seek to replace indigenous African religions. Though Atibuni (2011) asserts that many students exhibit high levels of religiosity because of the hardships of life , the findings of this study do not support his argument because adolescents from both low, moderate, and high SES all reported high religiosity. Generally, student reporting striking high levels of religiosity means that they are taught right from childhood the utility of religion and how it relates to other dimensions of life. This continues throughout their lives, even in high school (Snyder \& Shafer, 1996). As the students' awareness of the economic and social benefits of education increases, so does their commitment to aspects of life, such as religiosity, that promises fruitful benefits. Such commitment probably deters them from risky behaviors like alcohol drinking. Religious participation may deter risky behaviors by helping adolescents develop social networks, which provide social support and reinforce conformity to widely-accepted social norms thus limiting adolescents from using alcohol.

\section{Conclusions}

The moderate levels of SES of most of the adolescent students in Bushenyi- Ishaka Municipality schools who participated in this study come from western Uganda where propitious economic conditions support an increased family SES and more resources to educate their children. Low levels of alcohol use is good news to parents and guardians. This therefore, should encourage parents to put their children in boarding schools so they could benefit from an educational opportunity that tends to expose adolescents to less risky behaviors like alcohol consumption. 
Family Socioeconomic Status, Religiosity and Alcohol Use among Secondary School Adolescents in Bushenyi Ishaka Municipality, Uganda

\section{Reference}

Aggarwal, O.P., Bhasin, S.K., Sharma, A.K, Chhabra, P., Aggarwal, K, \& Rajoura, O.P. (2005). A New Instrument (Scale) for Measuring the Socioeconomic Status of a Family. Indian Journal of Community Medicine, 30 (4) 110-114.

Ahlström, S.K., \& Österberg, E.L. (2004). International Perspectives on Adolescent and Young Adult Drinking. World Health Organization (WHO). Global Status Report: Alcohol Policy. Geneva: WHO, 2004

Al-Kandari. F, Yacoub. K, Omu. F. (2001). Initiation factors for substance abuse. Journal of Advanced Nursing, 34(1): 78-85.

Atibuni, D, Z. (2011). Academic Attitudes, Religiosity, Locus of Control, and Work Readiness among University Students. (Unpublished Masters Dissertation). Mbarara University of Science and Technology

Batchelor, I. R. C. (1975). Henderson and Gillespie's textbook of Psychiatry for Students and Practitioners (10thed.). London: Oxford University Press.

Benjet, C., Borges, G., Medina-Mora, M., Fleiz, C., Blanco, J., Zambrano, J., \&, Ramirez, M. (2007). Prevalence and socio-demographic correlates of drug use among adolescents: Results from the Mexican. Adolescent Mental Health Survey. Addiction, 102, 1261-1268.

Blum, R.W., Beuhring, T., Shew, M.L., Bearinger, L.H., Sieving, R.E., and Resnick, M.D. (2000). The effects of race/ethnicity, income, and family structure on adolescent risk behaviors. American Journal of Public Health, 90(12), 1879-1884.

Brittany, C. H. \& Hernandez (2011). The religiosity and spirituality scale for youth.

Development and Initial validation. LSU Doctoral Dissertations. 2206.

Validity. Thesis for the Degree of Doctor of Philosophy of Louisiana State University.

Carter. M., McGee R., Taylor B., \& Williams., S. (2007). Health outcomes in adolescence: associations with family, friends and school engagement. Journal of Adolescence, 30, 5162.

Chikere, E.I.C., \& Mayowa, M.O. (2011). Prevalence and perceived health effect of alcohol use among male undergraduate students in Owerri, South-East Nigeria: a descriptive crosssectional study: BMC Public Health http://www.biomedcentral.com/1471-2458/11/118:16 
Collins, S.E., Malone, D.K., Clifasefi, S.L., et al. (2012). Project- based Housing First for chronically homeless individuals with alcohol problems: Within-subjects analyses of twoyear alcohol trajectories. American Journal of Public Health 102,511-519.

Dias P, Oliveira A, \& Lopes, C (2011). Social and behavioral determinants of alcohol consumption. Annals of Human Biology 2011, 38, 337-344.

Geckova, A., van Dijk, J.P., Groothoff, J.W. \& Post, D. (2002). Socio-economic differences in health risk behavior and attitudes towards health risk behavior among Slovak adolescents. Social and Preventive Medicine, 47, 233-239.

Goodman, E., \& Huang, B. (2002). Socioeconomic status, depressive symptoms, and adolescent substance use. Archives Pediatric Adolescent Med 156,448-453.

Hanson, M.D., \& Chen, E. (2007). Socioeconomic status and substance abuse behaviors in adolescents: the role of family resources versus family social status. Journal of Health Psychology. 12(1), 32-35.

Humensky, J.L. (2010). Are adolescents with high socioeconomic status more likely to engage in alcohol and illicit drug use in early adulthood? Substance Abuse Treatment, Prevention, and Policy, 5 (19), 1-10.

Jacob, N., \& Justice, N. (2012). Socioeconomic status from four sub-Saharan African countries. BMC Research Notes, 5, 380-396. doi: 10.1186/1756-0500-5-380

John-Langba, J., Ezeh, A., Guiella, G. (2006). Alcohol, drug use and sexual-risk behaviors among adolescents in four sub-Saharan African countries. http://paa2006.princeton.edu/download.aspx?sub mis sionId=61153.

Kabiru, C., W,Donatien Beguy, D., Joanna Crichton, J. \& Ezeh, C.J. (2010). Self-reported drunkenness among adolescents in four sub-Saharan African countries: associations with adverse childhood experiences. Child Adolescent Psychiatry Mental Health 4(17) 54-58.

Kaduri,P. (2008). Social Cognitive Determinants of Smoking Behavior Among Junior Secondary School Students, Kinondoni District, Dar as Salaam. (Unpublished masters dissertation).

Kokkevi, A., Richardson, C., Florescu, S., Kuzman, M., \& Stergar, E. (2007). Psychosocial correlates of substance use in adolescence: A cross-national study in six European countries; Drug and Alcohol Dependence 2007; 86 (1), 67-74.

Madu, S.N. \& Matla, M.Q.(2003). Illicit drug use, cigarette smoking and alcohol drinking 
Family Socioeconomic Status, Religiosity and Alcohol Use among Secondary School Adolescents in Bushenyi Ishaka Municipality, Uganda

behavior among a sample of high school adolescents in the Pietersburg area of the Northern Province, South Africa. Journal Adolescence, 26 (1), 121-136.Doi: 10.1016/S01401971(02)00120-3

Marklein, M. B. (2005). College gender gap widens: 57\% are women. USA Today. Retrieved on 15/05/2011 from www.usatoday.com/news/education/2005-10-19-male-collegecover_x.htm

Mbatia, J. \& Kilonzo, G. (1996). Drug abuse prevention. A hand book for educators in Tanzania; 11-16. MEHATA publication.

Mbiti, J. S (1992). Introduction to African religion (2nd ed.). East African Publishers. p. 15.

Mndeme, E (2003). Parental factors associated with drug use among youth attending the psychiatric unit at Muhimbili National Hospital. (Unpublished masters dissertation). Muhimbili University of Health and Allied Sciences.

O’Malley, P.M., Johnston, L.D., \& Bachman, J.G. (1998) Alcohol use among adolescents. Alcohol Health Res World, 22, 85-93.

Rajoura, O.P., Aggarwal, O.P., Bhasin, S.K., Sharma, A.K. \& Chhabra, P. (2005). A New Instrument (Scale) for Measuring the Socioeconomic Status of a Family. Indian Journal of Community Medicine, 30, No. 4, 110-114

Rehm, J., Mathers, C., Popova, S., Thavorncharoensap, M., Teerawattananon, Y., \& Patra, J. (2009). "Global burden of disease and injury and economic cost attributable to alcohol use and alcohol-use disorders," The Lancet, 373, 2223-2233.

Riggs, T. (2006). Religions and denominations. In the world mark Encyclopedia of religious practices; p.1. ISBN 9780787666125.

Rudatsikira, E., Muula, A. S., Siziya, S., \& Twa-Twa J. (2007). Suicidal ideation and associated factors among school-going adolescents in rural Uganda. BMC Psychiatry, 184-196 doi: 10.1186/1471-1244X-1187-1167.

Sanchez, Z., Oliveira L., \& Nappo, S. (2008). Religiosity as a protective factor against the use of drugs. Substance Use and Misuse, 43, 1476-1486.

Saunders, J. B., Aasland, O. G., Babor, T. F. de la Fuente, J. R., \& Grant, M. (2001). 
Development of the Alcohol Use Disorders Identification Test (AUDIT): WHO

Collaborative Project on Early Detection of Persons with Harmful Alcohol

Consumption-II. Addiction 1993; 88:791-804.

Simbee, G. (2012). Prevalence of substance use and psychosocial influencing factors among secondary school students in Dodoma Municipality. (Unpublished Masters Dissertation). Muhimbili University of Health and Allied Sciences.

Special Eurobarometer (2012). Discrimination in EU Believe in God. (European Commission). P.233. Retrieved 14 August 2013.

Tot, S.,Yazici, K., Yazici, A., Metin, O., Bal, N., \& Erdem, P. (2004). Psychosocial correlates of substance use among adolescents in Mersin, Turkey. Public Health 2004, 118, 588-593.

Wallace, J.M., Delva, J., O'Malley, P.M., Bachman, J.G., Schulenburg, E., Johnston, L.D., and Stewart, C. (2007). Race/Ethnicity, Religiosity and Adolescent Alcohol, Cigarette and Marijuana Use. Social Work in Public Health. 23, 193-213

Waeytens, K., Hulpiau, V., \& Jan, E. (2002). The organization of assessment: The impact on study behavior in higher education. Paper presented at the European Conference on Educational Research University of Lisbon.

Wichstrom L., \& Pederson, W. (2001). Use of anabolic-androgenic steroids in adolescence: Winning, looking good or being bad? Journal of Studies on Alcohol 2001, 62:5-13.

Wills, T. A, Gibbons, F X, Gerrard M, Murry VM, \& Brody GH. (2003). Family communication and religiosity related to substance use and sexual behavior in early adolescence: a test for pathways through self-control and prototype perceptions. Psychology of Addictive Behaviors, 17:312-323.

World Health Organization (2012). Global Status Report on Alcohol and Health. Geneva. 